\title{
How is electrical signal generated? \\ Structural and mechanistic investigations of $\mathrm{Na}_{\mathrm{v}}$ channels
}

\author{
Nieng Yan \\ School of Life Sciences, Tsinghua University, Beijing 100084, China \\ Department of Molecular Biology, Princeton, NJ 08540, USA
}

The voltage-gated sodium $\left(\mathrm{Na}_{\mathrm{v}}\right)$ channels are responsible for the initiation and propagation of action potentials. Being associated with a variety of channelopathies, they are targeted by multiple pharmaceutical drugs and natural toxins. We determined the crystal structure of a bacterial $\mathrm{Na}_{\mathrm{v}}$ channel $\mathrm{Na}_{\mathrm{v}} \mathrm{Rh}$ in a potentially inactivated state a few years ago, which is a homotetramer in primary sequence but exhibits structural asymmetry. Employing the modern methods of cryo-EM, we recently determined the near atomic resolution structures of a $\mathrm{Na}_{\mathrm{v}}$ channel from American cockroach (designated $\mathrm{Na}_{\mathrm{v}} \mathrm{PaS}$ ) and from electric eel (designated $\mathrm{EeNa}_{\mathrm{v}} 1.4$ ). These structures reveal the folding principle and structural details of the singlechain eukaryotic $\mathrm{Na}_{\mathrm{v}}$ channels that are distinct from homotetrameric voltage-gated ion channels. Unexpectedly, the two structures were captured in drastically different states. Whereas the structure of $\mathrm{Na}_{\mathrm{v}} \mathrm{PaS}$ has a closed pore and the four VSDs in distinct conformations, that of EeNa $\mathrm{v}_{\mathrm{v}} 1.4$ is open at the intracelluar gate with VSDs exhibiting similar "up"states. The most striking conformational differenc occurs to the III-IV linker, which is essential for fast inactivation. The III-IV undergoes a pronounced repositioning from $\mathrm{Na}_{\mathrm{v}} \mathrm{PaS}$ to $\mathrm{EeNa}_{\mathrm{v}} 1.4$, resulting in the insertion of the IFM fast inactivation motif on the III-IV linker into the corner enclosed by the S4-S5 and S6 segments in repeats III and IV of EeNav 1.4. Based on the structural features, we suggest an allosteric blocking mechanism for fast inactivation of $\mathrm{Na}_{\mathrm{v}}$ channels by the IFM motif. Structural comparison of the conformationally distinct $\mathrm{EeNa}_{\mathrm{v}} 1.4$ and $\mathrm{Na}_{\mathrm{v}} \mathrm{PaS}$ provides important insights into the electromechanical coupling mechanism of $\mathrm{Na}_{\mathrm{v}}$ channels and offers the 3D template to map hundredes of disease mutations. 